\title{
Electronic Waste: An Emerging Issue in Solid Waste Management in Australia
}

\section{Sunil Herat, $\mathbf{P h D}$}

Senior Lecturer, Griffith School of Engineering, Nathan Campus, Griffith University,

Queensland 4111, Australia.

Tel: +61737356682

E-mail address: s.herat@griffith.edu.au

\begin{abstract}
Waste from used electronic and electrical equipment, known as electronic waste or ewaste, is the fastest growing solid waste stream in the world today. Around 20 to 50 million tonnes of e-waste produced worldwide annually causing a serious social problem and an environmental threat to many countries. Australia has $12^{\text {th }}$ largest information and communication technology (ICT) market in the world and $4^{\text {th }}$ highest ICT contribution to GDP growth. Currently there are around 14 million computers in use in Australia with 3 million entering the market each year. Currently there is no national legislation to deal with used computers although extended producer responsibility through co-regulation is seen as a preferred option. The aim of this paper is to provide an overview of how Australia deals with this emerging issue given its geography and unique information technology market sector.
\end{abstract}

Keywords: Electronic waste; E-waste; Australia; Computers; Extended producer responsibility; Recycling; Re-use; Policy development; 


\section{Brief Biographical Notes about Author}

Dr Sunil Herat is a senior lecturer in waste management at Griffith University in Brisbane, Australia. His research interest is on how different countries deal with the problem of used electrical and electronic equipment or e-waste with special interest in developing countries. He is the research leader of the e-waste research group at Griffith University's Centre for Environmental Systems Research. Dr Herat is also the program coordinator of the postgraduate degree in waste management offered by Griffith University and in-charge of teaching postgraduate courses in solid waste management, hazardous waste management and cleaner production and ecoefficiency. He has supervised several coursework and research projects in this area. He is also the program coordinator of the Masters of Environmental Engineering degree offered by Griffith University. 


\section{List of Abbreviations}

$\begin{array}{ll}\text { ABS } & \text { Australian Bureau of Statistics } \\ \text { BFR } & \text { Brominated Flame Retardants } \\ \text { CPU } & \text { Central Processing Unit } \\ \text { CRT } & \text { Cathode Ray Tube } \\ \text { EOL } & \text { End of Life } \\ \text { EPHC } & \text { Environmental Protection and Heritage Council } \\ \text { EPR } & \text { Extended Producer Responsibility } \\ \text { ICT } & \text { Information and Communication Technology } \\ \text { PBB } & \text { Polybrominated biphenyl } \\ \text { PBDE } & \text { Polybrominated diphenyl ether } \\ \text { PC } & \text { Personal Computer } \\ \text { PCB } & \text { Printed Circuit Board } \\ \text { RoHS } & \text { Restriction of Hazardous Substances } \\ \text { WEEE } & \text { Waste from Electrical and Electronic Equipment }\end{array}$




\section{$1 \quad$ Introduction}

Electronic waste or E-waste is one of the fastest growing solid waste streams around the world today. According to the studies conducted in the European Union, e-waste is growing at a rate of $3-5 \%$ per annum or approximately three times faster than other individual waste streams in the solid waste sector (Schwarzer et al., 2005). Rapid uptake of information technology around the world coupled with the advent of new design and technology at regular intervals in the electronic sector is causing the early obsolescence many electronic items used around the world today. For example the average lifespan of a new model computer has decreased from 4.5 years in 1992 to an estimated 2 years in 2005 and is further decreasing (Widmer et al., 2005). In the United States, where it is believed to be the largest e-waste producer in the world, it is estimated that over 100 million computers, monitors and televisions become obsolete each year and that amount is growing each year (United States Government Accountability Office, 2005). Studies have also revealed that around 500 million computers will become obsolete in the United States alone between 1997 and 2007 (Yu et al., 2006). It is estimated that in China 5 million new computers and 10 million new televisions are purchased every year since 2003 (Hicks et al., 2005) and around 1.11 million tonnes e-waste is generated every year coming mainly from electrical and electronic manufacturing and production processes, end-of-life of household appliances and information technology products and import from other countries (Xuefeng et al., 2006). In Japan it is estimated that that some 9000 tonnes of homeused computers are scrapped every year, equivalent to 460,000 units, and this is expected to double or triple in next few years (Shimizu, 2003). In Canada it is estimated that 140,000 tonnes of waste electrical and electronic equipment 
accumulate in Canadian landfills each year (Feszty and J. Calder, 2007) while in Korea during 2004 over 3 million computers and 15 million mobile phones reached their end of life (Hyunmyung and Yong-Chul, 2006).

The same scenario applies to mobile phones and other hand held electronic items used in the present society. Each year over 130 million mobile phones in the United States and over 105 million mobile phones in Europe reach their end-of-life and are thrown away (Canning, 2006). As a result used electronic and electrical items, commonly known as e-waste, have become a serious social problem and an environmental threat to many countries worldwide. United Nations estimate that collectively the world generates 20 to 50 million tonnes of e-waste every year (Schwarzer et al., 2005).

The significant quantity of e-waste generated is not the only issue faced by the solid waste managers but also its composition. E-waste contains more than 1000 different substances, many of which are toxic metals such as lead, arsenic, cadmium, hexavalent chromium and flame retardants used in the plastics (Widmer et al., 2005). The regulations being developed around the world are demanding the replacement of many of these materials but they will still remain in the waste stream for some time.

The aim of this paper to provide an overview of how Australia deals with this emerging issue given its unique geography and the information technology market sector compared to other countries around the world. The paper will address issue of generation of e-waste in Australia and will investigate the initiatives undertaken by the governments and industry towards end-of-life management of this waste stream. 
Throughout the paper the emphasis will be on computer waste, which is a major component of e-waste in Australia.

\section{Generation of E-waste in Australia}

\subsection{About Australia and its information and communication technology}

Australia occupies an entire continent in the world map and is the sixth largest country in the world in land area after Russia, Canada, China, the United States of America and Brazil. It occupies some 7.6 million square kilometres with a total population of around 20 million. Australia has one of the most urbanised populations in the world with over $80 \%$ of the Australians living within 100 kilometres of the coast. The Australian federation consists of six States and two Territories; Australian Capital Territory, Western Australia, New South Wales, Victoria, Queensland, South Australia, Northern Territory, Tasmania. The largest State, Western Australia, is about the same size as Western Europe (Australian Government, 2007).

Australia's population concentrates on major capital cities accounting to $64 \%$ of the population (Australian Bureau of Statistics, 2007). The States such as New South Wales, Victoria and Queensland are heavily populated and are homes to majority of the businesses and industry. Due to the large area of Australia, the distance between the major population centers are significantly high making transport and logistics a major concern in any management system. 
The information and communication technology (ICT) industry in Australia which includes businesses related to computer hardware and software services, telecommunications, and communication cable and internet providers is the $12^{\text {th }}$ largest ICT in world. Australia also had the $4^{\text {th }}$ highest ICT contribution to GDP growth in the world (Australian Information Industry Association, 2007).

Australian computer industry considered to be the backbone of ICT consists of a number of major manufacturers as well as several minor players mainly as computer assemblers. Large global computer manufacturers such as Hewlett Packard, Dell, Acer, IBM, Toshiba and Apple dominate the Australian computer market, but they only account to $50-60 \%$ of the total market. The remainder is dominated by 'nonbrand' or 'white box' computers which are assembled from imported generic parts. Apart from this type of assembly there is no significant computer manufacturing industry in Australia.

\subsection{Computer use in Australia and generation of e-waste}

During the past few years Australian businesses and households have experienced a significant growth in the use of computers and Internet access. Australians are considered to be information technology loving people and are among the highest users in the world. According to Australian Bureau of Statistics (ABS), during 2003, $85 \%$ of all businesses in Australia have indicated use of a computer while $71 \%$ of them have reported having access to the Internet while $25 \%$ of all businesses having a web presence (Australian Bureau of Statistics, 2005a). As for the household use, a survey conducted by ABS has revealed that in 2005-06, 60\% of all the Australian 
households had home Internet access and $70 \%$ of all households had access to a computer at home. This is a significant growth from 1998 data where only $16 \%$ of all the households had access to the Internet and 44\% had access to a home computer (Australian Bureau of Statistics, 2005b). These data confirm the fact that the need to access the Internet from home is fuelling the purchase of home computers in Australia.

Given the unique market structure, it is not easy to determine the accurate data on the computer sales in Australia. IDC Australia estimates that over 3 million desktop and laptop computers are sold in Australia each year out of which laptops account for over 1.2 million (IDC Australia, 2005; IDC Australia, 2006).

In Australia during 2005, a major household electrical and electronic waste benchmark survey was conducted based on 1,702 telephone interviews with households across Australia representing most of the capital cities of Australia (Sydney, Melbourne, Brisbane, Adelaide, Perth and Canberra) but excluding Hobart and Darwin and regional areas. The survey also did not include commercial premises, government offices and educational institutions (Katos and Hoye, 2005).

The above survey which covered 4.2 million households in Australia and included most of the electrical and electronic goods except whitegoods revealed that 92.5 million electrical and electronic equipments are held in households representing an average of 22 items per household. As for the total number of computers held in households there are 4.3 million PC monitors, 4.2 million PC units/hard drives and 
1.2 million laptops representing on average 1 PC monitor, 1 PC unit/hard drive and 0.3 laptops per household surveyed (Katos and Hoye, 2005).

According to the Australian Bureau of Statistics in 2006 there were 8.1 million households in Australia (Australian Bureau of Statistics, 2004b). Thus assuming 1 PC (monitor and hard drive combined) and 0.3 laptops from the above survey resulting in 1.3 computers per household, it can be estimated that as at 2006 Australians had 10.5 million computers in their households.

As for the business use of computers, it is estimated that during year 2000, 641,000 businesses in Australia used 2.1 million computers (Meinhardt Infrastructure \& Environment Pty Ltd, 2001). This estimate excluded the agriculture sector. According to Australian Bureau of Statistics there are 754, 504 businesses in Australia as of June 2004 which includes all type of sectors (Australian Bureau of Statistics, 2004a). Thus, extrapolating the data from year 2000 study it can be conservatively estimated that at present there are at least 2.5 million computers in use within the Australian businesses.

Meinhardt study (Meinhardt Infrastructure \& Environment Pty Ltd, 2001) also estimated that during the year 2000 the Australian government sector, which included federal departments and agencies, state/territory departments and agencies, local government and other government agencies, used a total of 0.5 million computers. Extrapolating this figure taking into consideration the significant uptake of ICT within the government sector during the last 5 years, it can be conservatively estimated that 
at present there are at least 1 million computers in use within the government sector in Australia.

Using the above estimates, it can be conservatively estimated that there are at least 14 million computers in use within Australia.

As the national survey described in the previous section accounted only for the number electrical and electronic items in use, accurate information on the amount of e-waste generated in Australia is not available at the present time. One estimate made in 2001 stated that in 2006 there will be around 1.6 million computers disposed of in landfill, 1.8 million put in storage (in addition to the 5.3 million already gathering dust in garages and other storage areas) and 0.5 million recycled in Australia (Meinhardt Infrastructure \& Environment Pty Ltd, 2001).

\section{Problems Associated with E-waste}

Problems associated with computer waste are becoming well known in the scientific literature. In general computer equipment is a complicated assembly of significant number of different materials, many of which are highly toxic. The production of semiconductors, printed circuit boards, disk drives and monitors used in computer manufacture utilises many hazardous chemicals. Printer inks and toners often contain toxic materials such as cadmium. Computer Central Processing Unit (CPU) contains heavy metals such as cadmium, lead and mercury. Printed Circuit Boards (PCB) contain heavy metals such as antimony, silver, chromium, zinc, lead, tin and copper. 
In electrical and electronic equipment (EEE), lead is mainly used in cathode ray tubes (CRTs) in monitors, tin-lead solders, cabling, printed circuit boards and fluorescent tubes. The most significant use from the above list is the amount lead used in the manufacture of CRTs to shield the user from radiation. The main components of a CRT - the funnel, neck and the frit- contain between $0.4 \mathrm{~kg}$ and $3 \mathrm{~kg}$ of lead per monitor. Next to the CRTs, second largest source of lead in EEE can be found in tinlead solders used to connect many components together. Lead is used in tin-lead solders (typically 60\% tin and 40\% lead) due to its good conductivity, high corrosion resistance and high melting point which are all essential factors for a sound connection between the components (Five Winds International, 2001). Lead can affect almost every organ in the body including the nervous system, kidneys and reproductive system. The main effect of lead toxicity is on the central nervous system of the humans. High exposure of lead could also severely damage the brain and kidneys of the humans and could lead to miscarriage in pregnant women. High levels of lead could also affect the brain development of children and organs responsible for sperm production in men (ATSDR, 2005).

Hexavalent chromium has applications in electronic industry as anticorrosive coatings on metals, primers for coated metals and hard chrome. The compounds of chromium such as calcium chromate, chromium trioxide and lead chromate are well known human carcinogens. Cadmium is classified as toxic with a possible risk of irreversible effects on human health. Like lead, cadmium can accumulate in the body over time causing long term damage to human parts. In e-waste cadmium occurs in certain components such as chip resistors, infrared detectors and semi conductors. Copper is used within printed wire boards to provide electrical connections to various layers in 
the boards. Copper has significant environmental problems during its whole life cycle from extraction to end-of-life disposal (Brigden et al., 2005).

Waste computers also contain brominated flame retardants (BFRs) such as polybrominated biphenyls (PBB) and polybrominated diphenylethers (PBDEs). In computers BFRs are used in printed circuit boards, connectors, covers and cables. There is growing body of literature suggesting that BFRs have negative environmental and health effects hence be limited or replaced altogether (Barontini and Cozzani, 2006; Birnbaum and Staskal, 2004). Exposure of PBDEs to personnel working in e-waste recycling facilities and people in surrounding areas has been studied by researchers worldwide (Cai and Jiang, 2006; Jakobsson et al., 2002; Julander et al., 2005; Leung et al., 2006; Leung et al., 2007; Pettersson-Julander et al., 2004; Sjodin et al., 2001).

\section{Government/Industry Initiatives for dealing with E-waste}

Regulations and policies related to e-waste management have been developed in many countries worldwide. European Union leads the way in this regard through its well known Waste Electrical and Electronic Equipment (WEEE) and Restriction of Hazardous Substances (RoHS) Directives. This is closely followed by countries such as Japan, Taiwan and Korea and few States in the United States. Australia is still to reach the above levels as no national regulations or policies dealing with e-waste are in place at present. Australian state and federal governments are currently working together to impose regulations directed towards extended producer responsibility upon computer manufacturers and retailers with a view to managing this huge and 
growing waste stream. Currently there are efforts towards a co-regulatory framework for product stewardship, a federal and state government and industry cooperative push for industry to take primary responsibility for computer related products.

\subsection{Product stewardship in Australia}

Product stewardship requires manufacturers, importers, governments and consumers to have a shared responsibility for dealing with the environmental impact of a product throughout its life cycle. Such responsibility can be implemented in number of ways with varying levels of industry and government involvement. In Australia the Environmental Protection Heritage Council (EPHC) is charged with the responsibility of dealing with environmental impacts of various businesses in Australia. EPHC is a council made up of all Australian environment ministers and powered with responsibility of environment and heritage protection in Australia and New Zealand (Environmental Protection Heritage Council, 2007).

Co-regulation for product stewardship is a process where some form of government regulatory intervention is used in conjunction with specific industry product stewardship schemes. In December 2004 EPHC released an industry discussion paper on ‘Co-regulatory Frameworks for Product Stewardship’ (Environment Protection and Heritage Council, 2004) where the framework for co-regulation of a particular sector was described as made up of two main parts; a voluntary product stewardship agreement negotiated and signed by the industry or the industry association through EPHC and a regulatory safety net comprising laws that would be implemented through the government. 
Negotiations with the government (through EPHC) and the industry (through Australian Information Industry Association) to formulate a sustainable solution to the e-waste problem has taken place since 2004 but with limited success. The sticky point during these discussions was how to deal with the historical or orphaned computer waste where the current manufacturers are reluctant to contribute for obvious reasons. In October 2005 national environment ministers, through EPHC, concluded that coregulatory approaches proposed so far may not be suitable for computers and requested the officials to look at other options, including the regulatory options. In June 2006 Australian environment ministers directed their officials to report on regulatory options for product stewardship for computers by November 2006 taking into account this area presents significant challenges given the structure of the industry. At its meeting in Christchurch, New Zealand in November 2006, EPHC applauded Australian computer industry's efforts to develop a voluntary national computer recycling scheme. However, as the scheme has failed to engage with small importers and component distributors, EPHC recommended that introduction of a government-imposed regulatory national scheme for recycling be developed and introduced in 2007.

\subsection{Other federal initiatives related to $e$-waste}

Although the Australian federal government has not yet developed regulations and policies dealing directly with e-waste, it has developed number of other environmental initiatives which will have some impact on e-waste generated in Australia. National Packaging Covenant (NPC) is one such initiative where a co- 
regulatory agreement has been developed between the industries in packaging chain and all levels of government to reduce the impacts of packaging. The main objectives of the covenant include better product design, increased reduction, re-use and recycling of used packaging materials, reduced use of non-recyclable materials, reduced amount of used packaging materials going to landfill and reduced incidence of packaging being littered. There are many computer firms who are signatory to this covenant (National Packaging Covenant, 2007).

Australian federal government has also developed strict guidelines for export and import of used electronic equipment through its Hazardous Waste (Regulations of Export and Imports) Act 1989. This act regulates the export and import of hazardous waste within and outside Australia as required under the Basel Convention on the Control of Transboundary Movements of Hazardous Wastes and their Disposal. The Act regulates export and import of hazardous wastes, including waste electrical and electronic assemblies or scrap containing components such as accumulators and other batteries, mercury switches, glass from cathode ray tubes and other activated glass and polychlorinated biphenyl capacitors, or contaminated with constituents such as cadmium, mercury, lead or polychlorinated biphenyl to an extend that they possess any hazardous characteristics.

The above act, however, does not regulate the export and import of non-hazardous wastes including electronic assemblies consisting of metals or alloys, or waste electrical and electronic assemblies or scrap not containing the components described in above paragraph. The Act also does not regulate electrical and electronic assemblies (including printed circuit boards, electronic components and wires) 
destined for direct re-use, and not for recycling or final disposal (Re-use can include repair, refurbishment or upgrading, but not major reassembly). In 2004 it became apparent that large quantities of used ICT equipment were being exported from Australia for re-use or recycling in developing countries. As a result in 2005 the criteria for identifying electronic scrap were revised and new 'Criteria for the Export and Import of Used Electronic Equipment' was published to simplify the process of determining whether or not a particular waste is hazardous or not. Most computer waste is assumed to contain hazardous materials and therefore assumed to be hazardous unless proven otherwise. This is self assessment process conducted by exporters and importers with some auditing.

\subsection{State initiatives on e-waste}

In the absence of federal regulations many States around Australia have developed or in the process of developing their own initiatives to deal with the issue. Whether this is the right direction is arguable as piece meal solutions to a national problem is by far not the preferred option. An attempt is made in this section of the paper to describe some of these innovative initiatives.

The State of Queensland currently has no legislation specifically covering the e-waste issue. Existing Waste Management legislation covering how electronic waste might be dealt with exists under provisions that span three regulations. These are:

- Environmental Protection Regulation 1998;

- Environmental Protection (Interim Waste) Regulation 1996); and,

- Environmental Protection (Waste Management) Regulation 2000. 
Under Queensland regulations, domestic waste is not included as a part of regulated waste and as such, e-waste from commercial and industrial sources can therefore be legally disposed of through normal domestic waste collection as carried out by councils and disposed of in landfill. Although no concrete evidence is available there is strong belief that this is case.

Within the schedule of regulated wastes a number of substances including those found in e-waste are listed. This includes cadmium, lead and polychlorinated biphenyls (PCB's) and related substances and anything containing polychlorinated biphenyls or related substances. There is a process within the jurisdiction to detail with circumstances in which the environmental authority determines product to be regulated waste but it is first necessary to declare such waste. There have been no circumstances to date requiring such a determination for computer waste. Computer waste is therefore currently unable to be tracked. Due to this reason the actual quantity of e-waste that is currently deposited in landfill in Queensland is unknown as local government areas contacted state this waste stream is not tracked. There is an increasing level of awareness that electronic waste being sent to landfill now includes a broad and growing range of devices ranging from white goods to personal computers and cell phones and this is a serious problem. Two take-back days were held in Brisbane during 2006, one by the Brisbane City Council and other by Griffith University.

Queensland government Environmental Protection Authority (EPA) recently announced its 'byting' back at e-waste program where EPA would become the first government agency in Queensland to recycle its entire fleet of computer systems and 
replace them with monitors, hard drives, keyboards and mouses. In March 2007 EPA handed over 2300 computers to a recycling company preventing over 50 tonnes of ewaste going into a landfill and replaced with new equipment using $60 \%$ less power than the previous fleet (Queensland EPA, 2007). It also announced that a Japanese company specialising in e-waste management and recycling has approached the EPA expressing interest in exploring opportunities to recycle Queensland’s waste. EPA claims that taking up this option of recycling computer parts such as silicon chips, circuit boards, disk drives and monitors could benefit both countries.

The New South Wales (NSW) State government through its Department of Environment and Conservation (DEC) is leading the country on the development of Extended Producer Responsibility (EPR) policies aiming at producers taking the physical or financial responsibility for the environmental impacts of their products' life cycle. The EPR policy was introduced in NSW through Part 4 of the Waste Avoidance and Recovery Act 2001. The section 18 of the Act requires the Director General of the Department of Environment and Conservation (DEC) to publish an annual priority statement on EPR schemes (Department of Environment and Conservation, 2006). Although computers, mobile phones and televisions are included in this statement as sectors for priority focus, the possibility of extending this policy towards European Union's WEEE type regulations depends upon the regulations to be enforced by the federal government in the future.

As part of their sustainability path, NSW is also developing cohesive partnerships between government, business and the community to strengthen the sustainability initiatives and adopt innovative approaches to environmental protection and 
restoration. Known as Sustainability Compact, the DEC and its private sector partners make a public commitment to sustainability leadership. The Compacts are voluntary, negotiated agreements in which the parties commit to specific actions in areas such as sustainability leadership, sustainable products and services, efficient product and service delivery and environmental responsibility. The Sustainability Compact developed between the DEC and Hewlett-Packard Company (HP) is one example of the above. Through the Compact, DEC and HP will work in partnership on various sustainability priorities such as product stewardship relating computer hardware, printer supplies and packaging, environmentally preferable IT purchasing by consumers, business and government and enhanced environmental performance of HP sites and operations.

In Victoria, Sustainability Victoria is the government agency responsible for waste minimisation in that state. They work with government at all levels, the business sector and the community to implement an array of waste minimisation programmes ('Wastewise') and to promote recycled products and initiatives. It also collaborates with other government bodies responsible for protecting the environment. Sustainability Victoria’s predecessor EcoRecycle, has commissioned a number of reports on waste reduction including a 2004 publication on Electronic Waste Recycling Development Strategy for Victoria (Meinhardt Infrastructure \& Environment Pty Ltd, 2004) as well as supporting pilot projects for the collection of electronic waste in Victoria. Sustainability Victoria together with Hewlett Packard, are financing and sponsoring the current "Byteback" pilot programme in inner Melbourne with the end product being taken by the recycling company Sims ERecycling. 
Environment Victoria is also instrumental in the formation of an alliance of electronic recycling companies, environmental groups and local councils with the aim of accelerating government action on computer recycling. The alliance consists of Total Environmental Centre (non-profit organisation), SIMS Recycling Solutions, MRI Australia and TRI (all computer recyclers), Environment Victoria, New South Wales Local Government Association, Conservation Council of Western Australia and Australian Conservation Foundation. The coalition calling itself 'Lets do IT! Alliance' is requesting the federal and state governments to introduce mandatory extended producer responsibility schemes as soon as possible to stem the number of computers now being dumped in landfills instead of recycling.

In South Australia (SA), a central purchasing authority is responsible for the establishment of standing offer arrangements for computers and associated equipment including technical specifications. Individual departments then are able to place orders directly to the supplier under this framework.

In the selection of suppliers, a wide variety of eco-labelling and environmental criteria are used to differentiate the preferred manufacturer. The SA Government is currently in the process of replacing its computers with a major part of the business being held by HP. The Government has begun an equity programme with Zero Waste SA comanaging a refurbishing and donation scheme for the community. Zero Waste SA is a statutory authority created in 2004 within the SA Government for the purpose of promoting waste management practices that are directed both towards the elimination of waste or its supply to landfill and advancing the development of resource recovery. 
It is designed to be work with local government developing an integrated strategy on regional waste management and the development of waste management infrastructure for the State.

The Australian Capital Territory (ACT) is the only State or Territory in Australia where there is a ban on landfill disposal of e-waste. An e-waste collection and processing system is coordinated by the landfill contractor Thiess with e-waste collected at transfer stations, registered and sent to Sims E-Recycling in Sydney for recycling.

\section{Current End-of-life Management of E-waste in Australia}

In general End-of-Life (EOL) management of used computers could be achieved using one of the following methods:

- Storage at home or offices pending future management options;

- Re-use by giving used computers to friends and family, selling to employees or donating to schools and charity organisations although precaution must be taken when this option is practiced to send computers to developing countries to make sure they don't add to the e-waste problems.

- Disposal to commercial used computer recyclers;

- Disposal through computer take back schemes;

- Disposal through channels provided by local municipalities 
In the absence of any national framework for EOL of e-waste in Australia and also due to lack of knowledge and infrastructure for collection, recovery and recycling, it is widely believed that most of the used computers in Australia are ending up in storage in homes or offices or dumped in landfills.

Re-use involves the transfer of ownership of the used computer for continued use by some one else. In Australia, according the household electrical and electronic waste survey, it was found that giving computers away to family and friends is the most common form of disposal followed by council pick-up collection schemes. Re-use could take various forms including a 'closed system' where computers are transferred to an immediate circle of influence or 'open system' where ownership is transferred via commercial or non-profit organisations. This is a viable option given that different people have different needs as far as the computing is concerned. The Australian government’s 'Computer Technologies for Schools project' (CTFS) is a national project aimed at providing used computers to governmental and non-governmental schools around Australia. The program has delivered over 170,000 pieces of ICT since its inception (Australian Government, 2003).

Several non-profit organisations are involved in delivering the ‘open’ re-use of computers in Australia. For example Computer Bank operates in several States around Australia delivering computers to disadvantaged groups. Green PC is a similar organisation where computers are made available to low income communities. All these organisations rely upon volunteers and several organisations employ 'work-forthe-dole’ staff providing additional benefit to the society. 
Recycling and recovery of used computers involve disassembly of computers into constituent parts in order to recover raw materials such as metals and plastics that have been used in their manufacture. To date, Australia has not recycled much of its computers mainly due to lack of infrastructure due to not enough incentives to invest in reprocessing facilities. However, during last two years there has been a significant interest from major international companies to set up businesses in Australia. Sims ERecycling (Sims-E) and MRI are two major companies currently operating in Australia.

In the absence of a national framework in Australia few computer take back schemes are currently operated by major manufacturers as well as industry led organisations as described below:

As of 2003, Dell is the world's leading supplier of PCs. Dell is a preferred supplier to a number of major organisations around Australia and appears to have a significant share of the Government/Institution PC market. Dell utilises MRI as a recycler, refurbisher and re-marketer for its computer take-back programme in Australia. The public relations material states that Dell is engaged in product development for the purposes of reducing the environmental impact through Design for Environment (DfE), consumer awareness and computer take back for recycling. Dell has offered recycling services to Australians since 2003. During 2006 Dell recovered more than 215 tonnes of Dell and non-Dell branded equipment in Australia and New Zealand, a three fold increase from the previous year. Dell currently offers number of computer recycling options for Australian customers. This includes a national fee-based recycling service, free recycling with purchases in Sydney, Melbourne and Brisbane 
and several free community computer take back days in Sydney, Brisbane, Melbourne and Perth. Dell has also announced that as from end of 2006 the company would offer free recycling to Dell-branded computers owned by residential customers in Australia and New Zealand and extended its free recycling of any brands with the purchase of a new Dell PC to customers in all capital cities in Australia and New Zealand .

HP runs hardware take back programmes in Australia as well as ink and laser jet print cartridge take back. HP supports the rights of third-party re-manufacturers to compete in the marketplace with refilled product. It is recognised by HP that this is a specific market niche and HP does not design print cartridges to prevent remanufacturing. HP does believe that re-manufacturers should be responsible for the take back of their own product. HP also partners with eBay on the Rethink initiative which provides information, tools and solutions for selling, donating, or recycling used computers and electronics. The take back and recycling stance taken by HP provides them with a strong incentive to implement DfE. It operates two recycling plants in the US and one in Germany in partnership with Noranda Recycling. In Australia it cooperates with Sims E who takes its entire product. HP offers free recycling for commercial and enterprise customers in Australia provided they meet some minimum criteria.

MobileMuster is the official national recycling program of the mobile phone industry in Australia. The program collects and recycles mobile phone handsets, batteries and accessories from a network of over 1400 mobile phone retailers, local council, government agencies and businesses drop off points across Australia. The program is fully funded by the Australian Mobile Telecommunications Association (AMTA) 
through its members and is free to consumers and retailers (Australian Mobile Telecommunications Association, 2007).

Disposal of computers at landfills is widespread across Australia. Apart from the toxicity, waste computers also take up valuable landfill space. In Australia several major capital cities like Sydney and Melbourne are already facing landfill space problems. Unfortunately with landfill fees as little as \$27 per tonne (Commonwealth of Australia, 2006) there is not much of an incentive to move away from this practice.

The survey conducted recently on household electrical and electronic equipment revealed that $51 \%$ of used portable electrical and electronic items which include equipment such as walkmans and MP3 players were disposed of via the normal garbage bin collection system and essentially ending up in landfills (Katos and Hoye, 2005). Therefore, the size of the equipment plays a key role in the disposal method used by the households.

\section{Conclusions}

E-waste in Australia is growing at an alarming rate given its liking to information technology products. Widely known as the sleeping giant in solid waste sector, Australia's e-waste rate is set to climb to even higher levels compared to most other countries around the world as the country is experiencing a steady and growing information technology dependant economy. However, the Australian government lags behind many countries around the world in developing appropriate policies and regulations to deal with the e-waste issue. Although there is some progress in this 
regard, several external factors unique to Australia are inhibiting the progress. Given its uniqueness, the way forward may be to conduct rigorous research into policy development taking into account social, environmental, technical and economic aspects of solid waste management related to e-waste. Such research could comprise of but not limited to finding the answers to following questions:

- Are there suitable models for end-of-life management of electronic items that are fair for all the stakeholders?

- How feasible is European Union's WEEE style extended producer responsibility scheme in Australia?

- What are the issues that would lead to cooperation in purchasing policy between State and Federal agencies in Australia and its ability to incorporate extended producer responsibility?

Although there is an urgent need to develop policies and regulations to deal with the e-waste issue in Australia, it is important to conduct proper research into the topic to avoid the mistakes made by other countries around the world where regulations were rushed without any research related to local conditions.

\section{Acknowledgements}

The author wish to acknowledge Griffith University’s Centre for Environmental Systems Research for providing the funding assistance and Malcolm Wolski of Griffith University’s Information Technology group for on going strategic support. 


\section{References}

ATSDR, 2005. Lead: Agency for Toxic Substances and Disease Registry Fact Sheet. CAS 7439-92-1, United States Department of Health and Human Services.

Australian Bureau of Statistics, 2004a. Australian Bureau of Statistics Business Register. 8161.0.55.001.

Australian Bureau of Statistics, 2004b. Household and Family Projects in Australia. 3236.

Australian Bureau of Statistics, 2005a. Business Use of Information Technology Australia 2003-04. 8129.0.

Australian Bureau of Statistics, 2005b. Household Use of Information Technology Australia 2004-05. 8146.0.

Australian Bureau of Statistics, 2007. Regional Population Growth, Australia, 200506.3218.0

Australian Government, 2003. Computer Technologies for Schools. http://www.ctfs.edna.edu.au/ctfs/go (accessed on 9 July 2007).

Australian Government, 2007. The island continent - Australia. Department of Foreign Affairs and Trade. http://www.dfat.gov.au/aib/island_continent.html (accessed 9 July 2007).

Australian Information Industry Association, 2007. Australia's sophisticated ICT market. http://www.aiia.com.au/i-cms.isp?page=909 (accessed on 9 July 2007).

Australian Mobile Telecommunications Association, 2007, Mobilemuster. http://www.mobilemuster.com.au/?Page=691 (accessed on 9 July 2007).

Barontini, F. and Cozzani, V., 2006. Formation of hydrogen bromide and organobrominated compounds in the thermal degradation of electronic boards. Journal of Analytical and Applied Pyrolysis, 77(1): 41-55.

Birnbaum, L.S. and Staskal, D.F., 2004. Brominated flame retardants: Cause for concern? Environmental Health Perspectives, 112(1): 9-17.

Brigden, K., Labunska, I., Santillo, D. and Allsopp, M., 2005. Recycling of Electronic Wastes in China and India: Workplace \& Environmental Contamination., Greenpeace International.

Cai, Z.W. and Jiang, G.B., 2006. Determination of polybrominated diphenyl ethers in soil from e-waste recycling site. Talanta, 70(1): 88-90.

Canning, L., 2006. Rethinking market connections: mobile phone recovery, reuse and recycling in the UK. Journal of Business \& Industrial Marketing, 21(4-5): 320-329.

Commonwealth of Australia, 2006. Waste Management - Productivity Commision Inquiry Report. 38.

Department of Environment and Conservation, 2006. NSW Extended Producer Responsibility Priority Statement for 2005-06, New South Wales, Australia, p 34.

Environment Protection and Heritage Council, 2004. Industry Discussion Paper on Co-regulatory Frameworks for Product Stewardship, EPHC Australia.

Environmental Protection Heritage Council, 2007. Product Stewardship. http://www.ephc.gov.au (accessed on 9 July 2007).

Feszty, K. and Calder, J., 2007. E-Waste legislation grows in Canada, Green Supply Line. Green Supply Line.

Five Winds International, 2001. Toxic and Hazardous Materials in Electronics, Environment Canada. 
Hicks, C., Dietmar, R. and Eugster, M., 2005. The recycling and disposal of electrical and electronic waste in China - legislative and market responses.

Environmental Impact Assessment Review, 25(5): 459-471.

Hyunmyung, Y. and Yong-Chul, J., 2006. The practice and challenges of electronic waste recycling in Korea with emphasis on extended producer responsibility (EPR), Proceedings of the 2006 IEEE International Symposium on Electronics and the Environment.

IDC Australia, 2005. IDC Finds PC Market Hits 3 million Units in 2004.

IDC Australia, 2006. IDC Finds Notebook Market Ships over 1.2 million Units in 2005. 2.

Jakobsson, K. et al., 2002. Exposure to polybrominated diphenyl ethers and tetrabromobisphenol A among computer technicians. Chemosphere, 46(5): 709-716.

Julander, A. et al., 2005. Polybrominated diphenyl ethers - plasma levels and thyroid status of workers at an electronic recycling facility. International Archives of Occupational and Environmental Health, 78(7): 584-592.

Katos, G. and Hoye, J., 2005. Household Electrical \& Electronic Waste Survey 2005: Report of Findings, IPSOS.

Leung, A., Cai, Z.W. and Wong, M.H., 2006. Environmental contamination from electronic waste recycling at Guiyu, southeast China. Journal of Material Cycles and Waste Management, 8: 21-33.

Leung, A.O.W., Luksemburg, W.J., Wong, A.S. and Wong, M.H., 2007. Spatial distribution of polybrominated diphenyl ethers and polychlorinated dibenzo-pdioxins and dibenzofurans in soil and combusted residue at Guiyu, an electronic waste recycling site in southeast China. Environmental Science \& Technology, 41(8): 2730-2737.

Meinhardt Infrastructure \& Environment Pty Ltd, 2001. Computer \& Peripherals Materials Project, Environment Australia.

Meinhardt Infrastructure \& Environment Pty Ltd, 2004. Electronic Waste Recycling Development Strategy for Victoria, Multimedia Victoria, Australia.

National Packaging Covenant, 2007. http://www.packagingcovenant.org.au/ (accessed on 9 July 2007).

Pettersson-Julander, A., van Bavel, B., Engwall, M. and Westberg, H., 2004. Personal air sampling and analysis of polybrominated diphenyl ethers and other bromine containing compounds at an electronic recycling facility in Sweden. Journal of Environmental Monitoring, 6(11): 874-880.

Queensland EPA, 2007. Computer Recycling. http://www.epa.qld.gov.au/about_the_epa/public_reporting/epa_bulletin/epa_b ulletin_archives/issue_39_march_2007/computer_recycling/ (accessed on 9 July 2007).

Schwarzer, S., Bono, A.D., Peduzzi, P., Giuliani, G. and Kluser, S., 2005. E-waste, the hidden side of IT equipment's manufacturing and use.

Shimizu, K., 2003. New law requires recycling of PCs at consumers' expense, The Japan Times.

Sjodin, A., Patterson, D.G. and Bergman, A., 2001. Brominated flame retardants in serum from US blood donors. Environmental Science \& Technology, 35(19): 3830-3833.

United States Government Accountability Office, 2005. Electronic Waste: Strengthening the Role of the Federal Government in Encouraging Recycling and Reuse. GAO-06-47. 
Widmer, R., Oswald-Krapf, H., Sinha-Khetriwal, D., Schnellmann, M. and Boni, H., 2005. Global perspectives on e-waste. Environmental Impact Assessment Review, 25(5): 436-458.

Xuefeng, W., 2006. An agenda to move forward e-waste recycling and challenges in China, Proceedings of the 2006 IEEE International Symposium on Electronics and the Environment.

Yu, X.Z. et al., 2006. Distribution of polycyclic aromatic hydrocarbons in soils at Guiyu area of China, affected by recycling of electronic waste using primitive technologies. Chemosphere, 65(9): 1500-1509. 